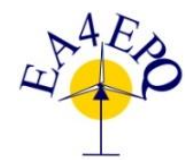

International Conference on Renewable Energies and Power Quality (ICREPQ'17)

Malaga (Spain), $4^{\text {th }}$ to $6^{\text {th }}$ April, 2017

Reneurable Energy and Pourer Quality. Fournal (RE\&PQJ)

ISSN 2172-038 X, No.15 April 2017

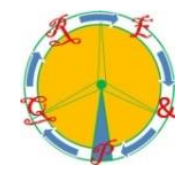

\title{
COOKING WITH THE SUN: TEACHING AND CAPACITING ABOUT SOLAR ENERGY
}

\author{
Juan Bello Llorente \\ Department of Construction and Civil Engineering \\ CIFP Someso \\ Rúa Someso 6, 15008 A Coruña (Spain) \\ Phone/Fax number: +34 881880001, e-mail: juanbello@edu.xunta.es
}

\begin{abstract}
.
When we want to teach thermal solar energy, the most exciting and successful didactic experiences are achieved using solar ovens and cookers.

This activity allows students to easily teach the most important theoretical concepts about solar energy and other technical subjects. It is also possible to talk about topics of ecological content, social, nutrition...
\end{abstract}

Students learn from the teacher's explanations, observing how the food boils, touching the hot pot and feeling the high temperature, smelling the aroma of cooked food and finally tasting the food. We can sum it up as "learning from the five senses".

At this point, students are eager to learn new knowledge and continually expose creative ideas to improve systems or to incorporate such knowledge into new applications.

This teaching tool is very flexible and it is possible to work at all levels of education, from kindergarten to university. It also enables people without previous studies to help their communities reduce their energy dependence on fuel wood or conventional fuels for cooking or heating their homes.

Using ovens and solar cookers allows communities to move towards sustainable development, use renewable energy, reduce deforestation and increase energy independence.

\section{Key words}

Solar cooking, Sustainable development, Community capacitation, Energy independence. Solar didactics.

\section{Introduction}

Cooking with the sun is a great educational tool to teach the main theoretical concepts about solar energy. Also it allows treating important technical concepts of different subjects: Physics, Mathematics, Sciences, Drawing, Technology...
Working with solar cookers allows analyzing many social issues and development in communities.

With this diversity of contents and the flexibility for its application, it is possible to work with very diverse groups: young children in kindergartens; Primary, secondary or vocational training students; University students or professional associations; People without specific qualification; Communities with few resources...

It is possible to work at different scales: using the sun to cook a person, a family or a community; make solar ovens by recycling materials or create the basis for a business producing solar ovens; Design bioclimatic constructions that require very little conventional energy to achieve comfort inside.

Cooking with the sun is a way to combat deforestation and energy dependence of communities, reaching higher levels of sustainability. It is also possible to preserve food and improve health conditions of people.

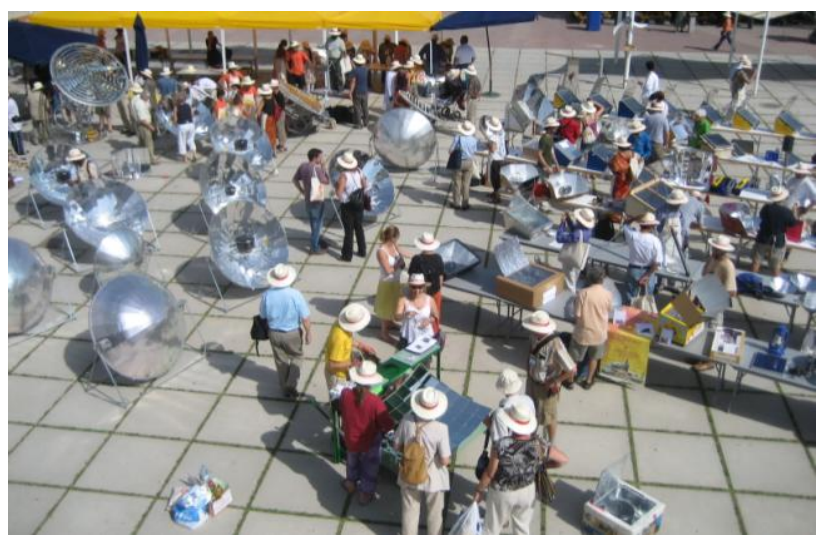

Solar Meeting at Science Museum. Granada. Spain. 2006

\section{Didactic resource}

Cooking with the sun? Is it possible? Yes, if we learn how. We can buy sophisticated equipment or we can use simple elements of self-construction. There are many commercial models with designs to work in different 
ways and also free designs so that each person can make one without having to buy it.

It is possible to study many technical and theoretical concepts. Technology: Thermal insulation, Orientation, Tilt, Greenhouse effect ... Physics: Heat transfer (radiation, conduction, convection) the color of surfaces (absorption or reflection), reflection and refraction of light, wavelength (visible light, heat) Temperature measurement... Mathematics: Geometry, calculation, graphic representation of measurement data (timetemperature)... Drawing: Geometry. Sketches and plans of construction, dimensions, decoration... Sciences: Solar movement, position of the sun every hour of the day and every day of the year, seasons, global warming, climate change...

The social and humanistic contents that can be analyzed are very diverse: resource economy, energy selfsufficiency, food and healthy diet, ecological food production, health care, solidarity, development aid to less favored communities, ecology, climatic change, recycling materials, the problem of waste, traditional use of renewable energies...

A learning process using the five senses: Students listen to the teacher's explanations (HEAR), watching how the food boils (SIGHT), touching the hot pot and feeling the high temperature (TOUCH), smelling the aroma of cooked food (SMELL) and finally tasting the food (TASTE). As expressed in the following photographic sequence:

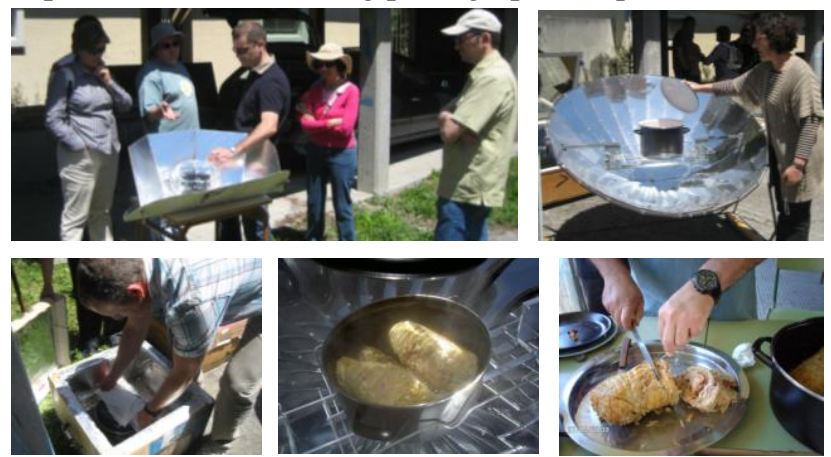

Hear - Sight - Touch - Smell - Taste

This activity greatly stimulates the creativity of students. During the process a brainstorm and proposals for improvement spontaneously develop. "And if we did...?"

Working with different types of solar ovens and cookers greatly facilitates the understanding of the operating principles and fundamental characteristics of the technological systems for the use of solar energy: typologies, features, components, etc. used by industry and green building.
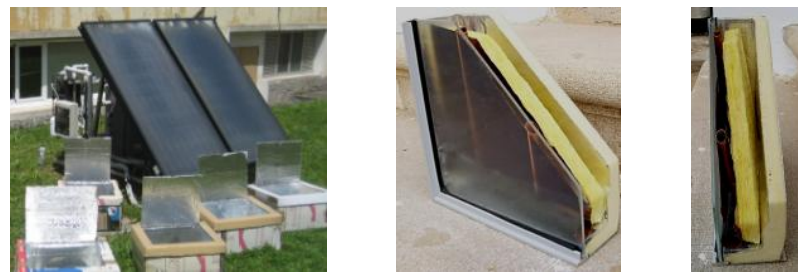

Identification of common characteristics with commercial products.
An important goal is to transfer the contents learned to the bioclimatic design of buildings and urban spaces as it will mean a significant energy saving throughout the time of use.

\section{Using adequate materials and techniques}

The initial proposal of work is to make a simple solar oven using materials available in the same place, low cost, using simple working techniques and tools easy to get. Materials that are easy to get in a European city surely will not be possible in a distant village in a developing country.
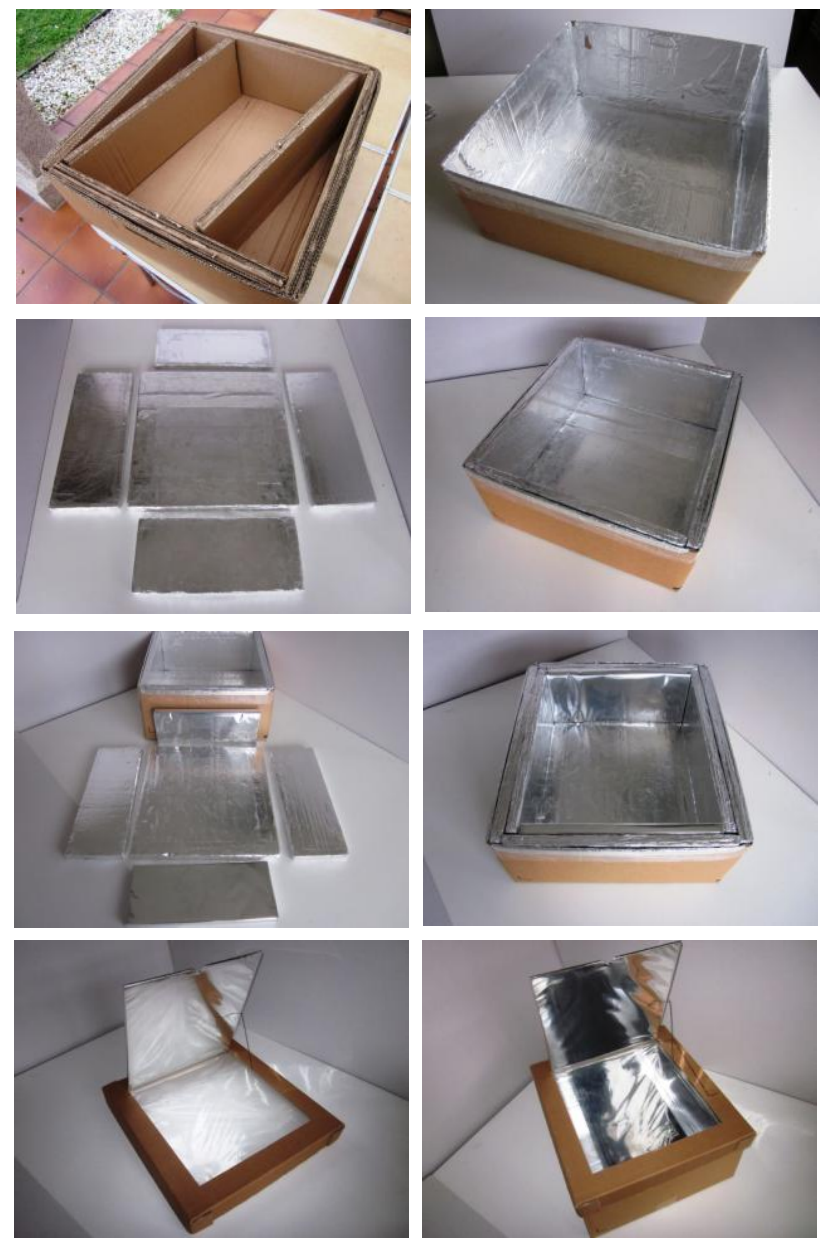

The photographic sequence shows phases of the construction process of a solar oven used as didactic model of research in bioclimatic construction.

A cardboard box can be replaced by a wooden box, a basket or a construction with adobes. Insulation can be achieved by recycling commercial insulation, or using other waste materials such as crumpled newspaper, cardboard sheets or wood chips; Also natural materials such as straw, wool or animal hair.

When it is necessary to move scarce material, it is important to verify that there is no valid alternative in the destination and to reduce its use to the maximum. For example, an aluminum foil can be replaced by the inside of a bag of chips or tetra brick. 
To complete the oven it is necessary to make greenhouse effect with a transparent cover: window glass, rigid or flexible transparent plastic.

To convert sunlight into heat energy you need a black, thin-walled pot with cover to keep the heat and humidity inside.

\section{Cooking with the sun}

There are many models of ovens and solar cookers, each one has specific characteristics. It is interesting to practice with several types to gain more knowledge about solar energy. For example:

Accumulation ovens: Low temperature cooking, Collection of sunlight, Transformation of light into heat, Greenhouse effect, (But... is that not what is happening to the planet?), Conservation of heat, Isolation, Energy economy, Orientation, Slope with the time of year, Applications for bioclimatic architecture...

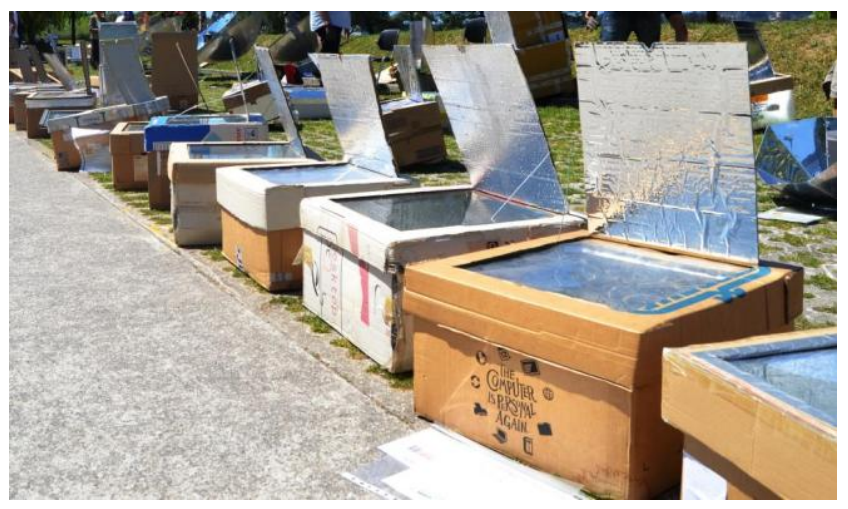

Low cost accumulation solar ovens

Parabolic concentrator cooker: Multiple mirrors. Parabolic geometry. Only the pot is hot. Concentration on a focal point. Movement of the sun. Solar azimuth and altitude. Concentration power. Temperature measurement. The cooling wind...

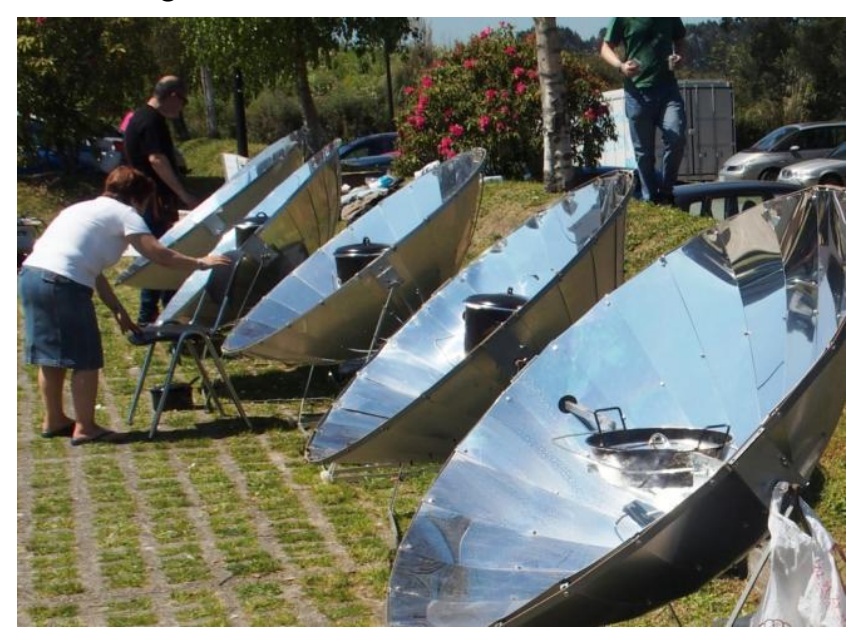

Parabolic concentrator cookers

What can we cook with the sun? It is possible to cook a lot of recipes: Starter dishes, Bread, Pizza, Rice, Pasta, Omelets, Vegetables, Meat, Fish, and Desserts.
Prepare a complete and balanced menu allows talking about nutrition, diets and ecological production of food and availability of food for all humanity.

Solar cooking is easily adapted to culinary traditions of each culture.

\section{Resource for the development of communities}

More sustainable communities: Introducing solar cooking in development aid programs in disadvantaged areas reduces dependence on conventional fuels. The use of firewood for cooking causes problems of deforestation in many areas of the planet.

Improving the economy of families: Cooking with the sun is free and does not require wood or other conventional fuel. Families with economic difficulties can reserve these valuable resources for not sunny periods. Making a solar oven with nearby resources readily available at the site reduces dependence on external supplies in communities.

Food security: The kitchens and solar ovens also allow the pasteurization of water and other products, as well as to desiccate food or prepare preserves. This contributes to improving food reserves for times of scarcity.

Protection of health: Cooking with the sun prevents health problems caused by the smoke inside the house by using low-quality and inefficient facilities. Solar cookers allow a thermal treatment of water to eliminate pathogens.

Solar heating of buildings: It is possible to reproduce the operating principles of solar ovens in the design of buildings to be heated free with the sun in winter and avoid excessive heat in summer. An example of a building that does not need heating system in winter or air conditioning in summer is in the professional training school "CIFP Someso" where I work in A Coruña (Spain). The name of this building is "A Vieira" (Scallop in Galician language)

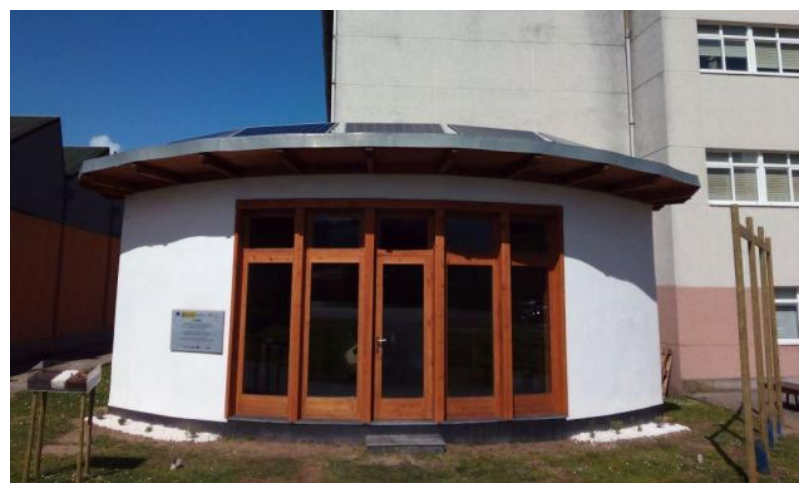

Bioclimatic Experimental Module "A Vieira" in CIFP Someso. A Coruña. Spain

\section{Training Trainers}

It is necessary to train people capable of teaching families in their communities. Trainers need to perfectly 
understand the principles of operation of solar cookers and ovens. They need to know how to make ovens of different types with the materials available in each location. It is especially important to know the habits of people, families and communities to successfully adapt solar cooking programs.

Personally I have taught the construction and use of solar ovens in Spain, Cuba, Portugal, Italy and Germany with very interesting results. I have participated in international meetings in Spain and Portugal with specialists in solar cooking from many countries in the world.

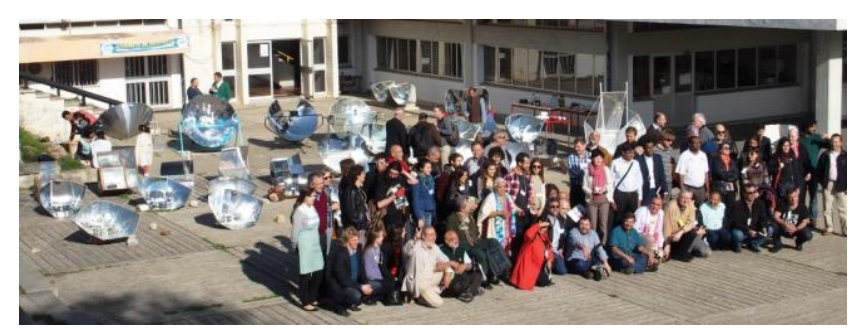

CONSOLFOOD 2016. University of Algarve. Portugal.

A part of my teaching activity focuses on these fundamental directions

- $\quad$ Training teachers to use ovens and solar cookers as an important didactic resource for solar energy.

- Training people, families and communities to improve their energy autonomy.

- Training specialists in bioclimatic construction and bioconstruction to make health and environmentfriendly houses.

\section{Training imparted}

The following are the most important training activities in my personal career in this area:

I have given 6 specific courses for teachers with duration of $20 \mathrm{~h}$ with a total of 120 participants. As a result, each teacher builds his own solar oven (sometimes up to two different models), experimenting with a minimum of three different models of ovens and solar cookers, acquiring the necessary experience to use the solar cooker as a teaching tool in his classes.

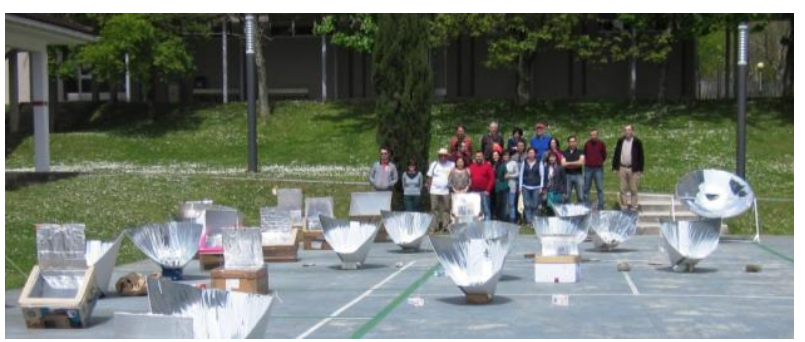

Course at teachers training center CAFI in Santiago de Compostela. Spain

I have given 12 workshops of introduction to the solar kitchen with the participation of 240 people (teachers, students and general public). The minimum duration of the workshops is 4 hours and the structure is adapted to the characteristics of each group. The main points to develop are: collective construction of low cost solar ovens, practices with different models of ovens and solar cookers and tasting of prepared dishes.

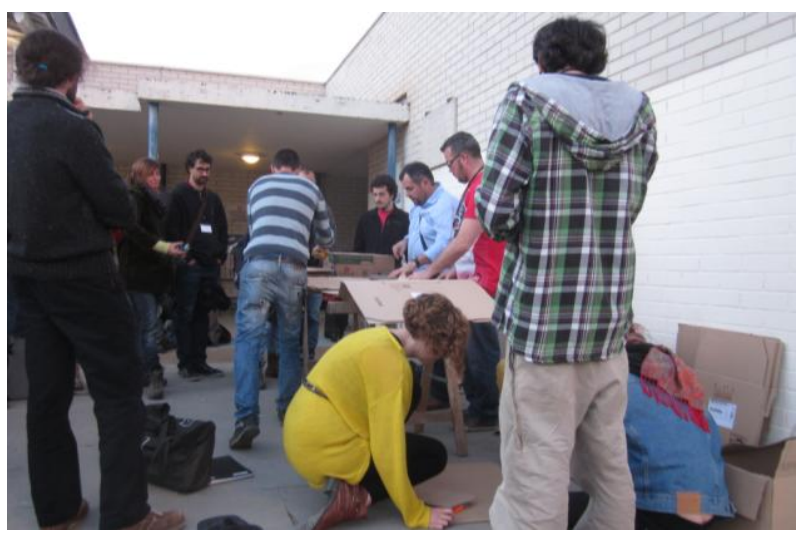

Workshop for students at the University of Girona. Spain

At least 20 informative activities of exhibition, demonstration of operation and explanation of solar cookers and ovens aimed at teachers, students and general public, with scope of variable intervention, from local to international and an estimated participation in 1000 people.
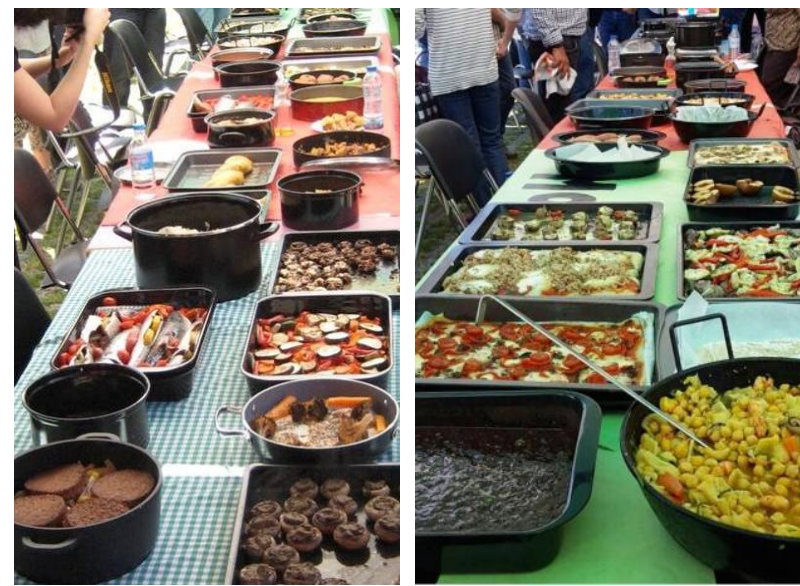

Numerous dishes cooked with the sun. A Coruña. Spain

The training activities in which I have participated have been organized by teacher training centers in different cities, universities, primary, secondary and vocational training schools, associations, municipalities and other entities of public administration.

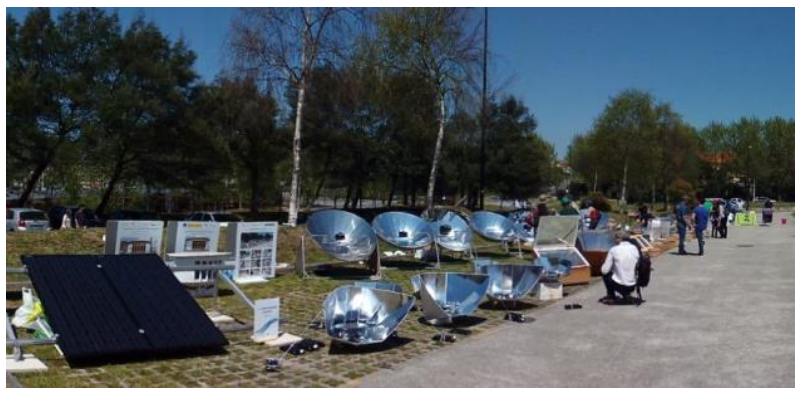

Solar meeting at University of A Coruña. Spain 


\section{Evaluation}

95\% of the participants have qualified this activity as positive or very positive. This assessment is based on specific satisfaction forms or on direct comments about the activities.

\section{Conclusions}

Cooking with the sun is an excellent didactic tool for solar energy. It is very flexible and valid for people of all ages and level of training.

The technology required is simple and adapts easily to a wide variety of manufacturing materials, climates and cooking customs.

Organizing solar cooking programs facilitates the sustainable development of disadvantaged communities. It is a good resource for reducing deforestation, energy dependence and climate change. These programs provide ecological, economic, health and nutrition improvements.

It is very important to train trainers who know the customs of the communities so that the programs are successful.

Moving the operating principles of solar cookers to building construction and urban design transforms the scale of intervention and multiplies the success of the results.

The results achieved open up interesting opportunities for innovation projects in the field of appropriate technologies.

\section{References}

[1] Solar Cookers. How to make, use and enjoy, $10^{\text {th }}$ ed. Solar Cookers International, Sacramento, CA, 2004

[2] Cocinas solares:Manual de uso y construcción., S.A. Progensa. Promotora general de estudios, Mairena del Aljarafe, Sevilla, España, 2004

[3] D. Casado, Hornos solares con cajas de cartón, 2nd ed. Arre, Navarra, España, Pamiela, 2004

[4] J.M. Jiménez, Ingenios Solares: Manual práctico para la construcción de aparatos sencillos relacionados con la energía solar, Arre, Navarra, España, Pamiela, 2013 